\title{
QUE COMUNIDADE? QUE AGÊNCIA HUMANA? SANDEL E OS LIMITES DO COMUNITARISMO
}

\section{WHICH COMMUNITY? WHICH HUMAN AGENCY? SANDEL AND THE LIMITS OF COMMUNITARIANISM}

\author{
Pedro Marques Neto* \\ Theófilo Miguel de Aquino** \\ Recebido: 04/2017 \\ Aprovado em: 10/2017
}

\begin{abstract}
Resumo: Dos debates originados pela publicação de A Theory of Justice, de John Rawls, a controvérsia entre liberais e comunitaristas talvez seja a mais frutífera. Esse debate multifacetado possui várias portas de entrada e apresenta inúmeras perspectivas interpretativas. Nosso artigo recorta um argumento comunitarista contra Rawls que implicou uma revisão significativa de suas ideias. Trata-se da crítica de Michael Sandel ao projeto filosófico rawlsiano. Nossa intenção é expor o desenvolvimento desse ponto do debate para, ao fim, argumentar pelo fracasso das objeções levantadas por Sandel. Argumentamos que a teoria da justiça de Rawls, em que pese as revisões que sofreu, sobrevive em seus pontos principais aos ataques comunitários de Sandel.
\end{abstract}

Palavras-chave: Liberalismo; Comunitarismo; Agência; Sujeito enraizado.

\begin{abstract}
Among the debates arisen from The Theory of Justice, by John Rawls, liberals vs communitarians controversy is probably the most fruitful one. This multicolored discussion has several entrance doors and holds uncountable interpretative perspectives. Our article draws on one specific argument against Rawls, which implied a significant revision of his ideas. It is Michael Sandel's critic to the Rawlsian philosophic project. Our intention is to expose the development of this share of the debate in order to argue for the failure of Sandel's objections. We argue that the Rawlsian theory of justice stands still on its central features despite the communitarians attacks by Sandel.

Keyword: Liberalism; Communitarianism; Agency; Embedded self.
\end{abstract}

\section{Introdução}

Recortamos, nesse artigo, o debate entre liberais e comunitaristas a partir das críticas de Sandel aos limites do liberalismo rawlsiano da $A$ Theory of Justice para argumentar pela sustentação das ideias de Rawls frente às críticas sofridas. Em que pese as revisões efetuadas em sua teoria após a discussão, argumentaremos que seus elementos estruturantes podem permanecer intocados. Diante disso, fracassa a tentativa comunitarista de Sandel de suplantar o liberalismo de Rawls por uma nova ontologia social.

$\mathrm{O}$ artigo vem estruturado da seguinte maneira. Na próxima seção, ofereceremos uma breve contextualização do debate entre liberais e comunitários. A seção III reconstrói o liberalismo deontológico de Rawls e as

\footnotetext{
* Mestrando em Direito e Desenvolvimento, FGV/SP, São Paulo, Brasil; pedro.neto2016@gvmail.br

** Mestrando em Direito e Desenvolvimento, FGV/SP, São Paulo, Brasil; theofilo.aquino2016@gvmail.br Problemata: R. Intern. Fil. v. 8. n. 3 (2017), p. 228-242 ISSN 2236-8612 doi:http://dx.doi.org/10.7443/problemata.v8i3.33770
} 
objeções levantadas por Sandel. A seção IV explora duas respostas liberais ao projeto filosófico de Sandel, expondo os limites de seu comunitarismo. A primeira resposta realça os limites da sua concepção de comunidade; a segunda, da sua concepção de agência humana. Na seção $V$, tomamos parte no debate a favor do projeto liberal de Rawls. Argumentamos que a teoria rawlsiana possui ressalvas quanto às suas condições de aplicação que a torna pouco vulnerável às críticas formuladas por Sandel. Finalmente, a seção V apresenta as considerações finais.

\section{O debate liberais-comunitários}

Quais normas regulam de forma legítima as relações legais, econômicas e sociais de uma comunidade política? Organizamos nossas vidas em comunidades políticas, desenvolvemos relações sociais complexas e desenhamos instituições políticas para regular nossas interações sociais, visando ordená-las segundo algum propósito social mais amplo e prédeterminado. Garantir a legitimidade moral de nossas instituições e da ordem social resultante é o principal objetivo da justiça. A concepção de justiça mais proeminente no debate contemporâneo é uma versão liberal, inspirada em Rawls e pensada originalmente como crítica e via alternativa ao utilitarismo.

Como projeto político, essa versão liberal aproxima-se de uma defesa da social democracia, com enfoque na proteção de direitos individuais e liberdades civis, bem como na promoção de políticas de combate às desigualdades sociais, na medida em que proporcionem a melhoria do bemestar geral da parcela mais pobre da população. A combinação de direitos individuais e justiça social, portanto, constitui o pilar do projeto político liberal, estabelecendo uma relação de precedência desses dois fatores sobre os demais fins coletivos. Essencial à promoção desse pilar é a necessidade de neutralidade na atuação estatal: a ideia de que o Estado deve abster-se de promover ou punir determinadas concepções de vida boa, mas deve promover um cenário político neutro dentro do qual diversas (e por vezes conflitantes) concepções de bem e de vida boa possam florescer e serem perseguidas (Kymlicka, 1989, p. 1).

O projeto político do liberal recebeu inúmeras críticas por valorizar excessivamente a defesa das liberdades civis e da justiça social em detrimento de outros valores sociais considerados de igual relevância por seus críticos. Eles acusam o liberalismo de possuir uma visão distorcida de indivíduo, bem como de sociedade: indivíduos são retratados como agentes racionais, egoístas, interessados tão somente na defesa de seus direitos fundamentais inalienáveis; indivíduos são socialmente isolados, desprovidos de laços 
humanos, valores ou tradições dos quais sejam incapazes de se desprender; por sua vez, as sociedades liberais são desprovidas de histórias e tradições a serem preservadas, sendo sempre possível recriá-las ex nihilo, a qualquer instante (Walzer, 1990, pp. 7-9). Seriam negligenciados pelo retrato liberal elementos comunitários que conferem unidade aos diversos indivíduos e forjam organizações sociais coesas, com histórias, tradições e valores compartilhados. Uma vez reconhecidos pelo projeto político liberal, esses elementos ressaltariam a importância de valores sociais concorrentes à justiça, o que exigiria o desenvolvimento de um projeto político voltado à consecução do bem comum e contrário à pretensão liberal de neutralidade.

As objeções ao projeto político liberal estão relacionadas a divergências teóricas mais profundas a respeito do projeto filosófico do liberalismo.

${ }^{1}$ Concebido como crítica filosófica ao projeto liberal, o comunitarismo não possui homogeneidade metodológica ou normativa entre seus autores, acomodando divergências internas que tornam imprecisas afirmações a respeito da compatibilidade dos argumentos comunitários e liberais. Contudo, seria possível identificar, segundo Forst, uma tese suficientemente geral da objeção comunitária, capaz de englobar as diferentes vertentes sob o mesmo rótulo:

\begin{abstract}
It states [the general communitarian thesis] the 'context of justice' has to be a community that, in its historically evolved values, practices, and institutions - in its identity, in short - forms the normative horizons that are constitutive of the identity of its members and thus of the norms of justice. Only within these horizons of value is it possible to pose questions of justice and answer them with reference to what is good and valid for the community against the background of its evaluations and its self-understanding (Forst, 2002, p. 2).
\end{abstract}

Em comum, portanto, as objeções comunitárias ressaltarão o nível de abstração empregado pelo projeto liberal no seu esforço de definir e qualificar a justiça, supostamente insensível às condicionantes sociais e culturais que incidem sobre os indivíduos e sobre a organização de uma comunidade política. Uma dessas críticas, com contornos próprios, foi elaborada por Michael Sandel, tendo como alvo principal o projeto filosófico liberal de John Rawls. A seção seguinte reconstrói o liberalismo deontológico de Rawls e delineia a crítica comunitária de Sandel ao projeto rawlsiano.

\title{
O liberalismo deontológico de rawls e a crítica comunitarista de sandel
}

Sandel é claro ao afirmar que seu objetivo em Liberalism and the Limits of Justice é questionar o projeto político e moral do liberalismo deontológico, uma versão 
proeminente do liberalismo derivada de Kant (Sandel, 1998, pp. 1-15). A base desse projeto político é a constatação de que as sociedades contemporâneas são marcadas pelo fato do pluralismo político, de forma que a organização social mais adequada seria aquela que conseguisse se manter neutra em relação às diversas concepções de bem defendidas por seus cidadãos. Para alcançar essa finalidade, os princípios reguladores dessa sociedade não podem estar sujeitos às contingências de uma busca pela maximização do bem-estar social ou pela promoção da concepção de bem socialmente predominante. Seria necessário conferir bases mais sólidas e menos contingentes à organização da estrutura social, que respeitasse a diversidade de concepções de vida boa existentes no tecido social. Por essas razões, a primazia da justiça sobre as demais virtudes sociais, a prioridade dos direitos sobre concepções do bem e a oposição a concepções políticas e morais utilitaristas são algumas das principais características desse projeto político liberal.

Mais especificamente, Sandel pretende desafiar a versão mais atualizada e bemformulada do liberalismo deontológico proposta por John Rawls em $A$ Theory of Justice. Seu objetivo, contudo, não é o de questionar os princípios de justiça derivados por Rawls, mas de questionar o próprio status que a justiça adquire no projeto rawlsiano: Justice is the first virtue of social institutions, as truth is of systems of thought (...) being first virtues of human activities, truth and justice are uncompromising (Rawls, 1999, p. 3). Essa passagem esclarece o ponto do projeto rawlsiano a ser atacado por Sandel: a tentativa de elevar a justiça ao status de primeira virtude dentre as demais virtudes sociais (primazia da justiça).

Sandel distingue duas formas pelas quais a primazia da justiça deve ser concebida. Por um lado, a primazia da justiça deve ser entendida como uma exigência moral (Sandel, 1998, p. 16-17). Trata-se de um dever de predominância da justiça frente aos demais interesses políticos e sociais. Por ser a primeira virtude social, a justiça impõe certas obrigações morais que não podem estar sujeitas aos cálculos de custo-benefício social; razões consequencialistas e contingenciais não podem se contrapor, muito menos predominar sobre considerações de justiça. Por outro lado, a primazia da justiça deve ser entendida no seu sentido fundacional (Sandel, 1998, pp. 17-18). A justiça precede as demais virtudes sociais pois seus princípios são derivados de maneira autônoma por meio de um método que não pressupõe finalidades, propósitos humanos ou qualquer concepção específica de bem. Trata-se de uma exigência epistemológica de primazia, relacionada à busca de Rawls por um ponto de vista arquimediano por meio do qual avaliar a estrutura básica da sociedade: um ponto de vista que nos possibilite enxergar as estruturas sociais de longe, além da nossa posição específica no tempo e no espaço sociais, mas não de tão longe, de forma que ainda assim qualquer pessoa racional seja capaz de adotá-lo (Sandel, 1998, p. 17).

Para Sandel, a primazia da justiça está relacionada a algumas noções correlatas presentes no liberalismo deontológico. Uma delas é precedência do Eu sobre seus fins (Sandel, 1998, pp. 17-18). Em sua versão deontológica, o liberalismo compreende o indivíduo como um receptáculo de objetivos e experiências, mas cuja identidade nunca se resume a essas sensações; será sempre possível identificar por trás de todo o emaranhado de emoções e desejos a que estamos sujeitos um elemento unificador 
que confere sentido aos diversos atributos do Eu (Sandel, 1998, pp. 19-20). De acordo com essa visão possessiva do $\mathrm{Eu}$, o elemento unificador será sempre capaz de escolher seus desejos e sensações, na medida em que concebe o indivíduo como um sujeito dotado de completa autonomia decisória: even a dominant end must be chosen from among numerous possibilities (Sandel, 1998, p. 19). Devido à continuidade do Eu em contraposição à intermitência dos fins, o liberalismo deontológico confere maior importância ao sujeito capaz de escolha do que aos objetivos eventualmente escolhidos por ele. Enquanto a capacidade de autodeterminação é um elemento inerente à noção do Eu, seus fins são características acidentais, constantemente sujeitas a mudanças de opiniões e a escolhas de cada indivíduo.

A precedência do Eu sobre seus fins confere sentido à primazia da justiça sobre as demais virtudes sociais (Sandel, 1998, pp. 21-24). É precisamente por sermos seres dotados de certo grau de autonomia que a sociedade será mais bem organizada ao implementar princípios que não pressupõem concepções abrangentes de bem, possibilitando que os próprios indivíduos - e não a sociedade - determinem com base em quais valores conduzir suas respectivas vidas. Qualquer arranjo político em sentido contrário falharia em tratar seus cidadãos com dignidade, pois privilegiariam a heteronomia em prejuízo da autonomia, bem como os tratariam como um conjunto homogêneo, e não como uma pluralidade diversificada e heterogênea de valores e identidades. A escolha de qual concepção de bem seguir passaria a ser definida externa e homogeneamente pela comunidade política, e não mais internamente por cada cidadão. Em um arranjo político como esse, os fins tomariam, inadequadamente, precedência sobre o Eu.

Em linhas gerais, esse é o projeto do liberalismo deontológico, representado recentemente por Rawls. Contudo, argumenta Sandel, para que para a noção de primazia da justiça seja correta, algumas suposições do que seja o indivíduo feitas pelo liberalismo deontológico precisam ser igualmente procedentes: precisamos ser indivíduos de um certo tipo e nos relacionar com nossos fins de uma certa maneira (Sandel, 1998, pp. 10-11). Mais especificamente, precisamos anteceder nossos fins, escolhendo-os ao invés de descobri-los, assim como precisamos ser uma pluralidade de indivíduos, com cada Eu distinto dos demais, e não uma unidade com fins e valores compartilhados que constituem nossa identidade comum. É precisamente essa concepção possessiva de indivíduo que Sandel questionará. Como ele próprio admite, o debate se transforma numa investigação na área da antropologia filosófica (Sandel, 1998, p. 50).

Os principais elementos da crítica de Sandel estão presentes na sua análise da posição original. A posição original é um elemento central na teoria rawlsiana da justiça (Freeman, 2016). Rawls a imaginou como uma forma de oferecer um ponto de vista justo e imparcial por meio do qual refletir sobre os princípios de justiça. $\mathrm{Na}$ posição original, nós somos convidados a imaginar indivíduos livres e iguais que precisam definir os princípios de justiça que governarão nossas instituições políticas e sociais mais básicas. Para garantir a imparcialidade nos seus julgamentos, os indivíduos são submetidos ao véu da ignorância, que lhes retirará qualquer conhecimento específico sobre suas características individuais, concepções de bem 
ou história de vida. Dessa forma, a posição original poderia ser interpretada de duas maneiras. A primeira concebe-a como o mecanismo pensado por Rawls supostamente capaz de oferecer o ponto de vista arquimediano pelo qual avaliar a justiça de nossas práticas institucionais. A segunda enxerga-a como um processo de justificação moral dos princípios de justiça rawlsiano. Interpretada da segunda maneira, porém, Sandel indaga se a posição original realmente possuiria a força justificatória dos princípios de justiça pressuposta por Rawls (Sandel, 1998, pp. 104-132).

Segundo argumenta, contratos do mundo real (actual contracts) são meros fatos sociais, logo incapazes de justificarem a si próprios (Sandel, 1998, pp. 105-109). Qualquer tentativa de recorrer a contratos de segunda ordem (contratos gerais estipulando que contratos específicos geram obrigações morais) apenas postergaria, mas não solucionaria, o problema da força justificatória dos contratos. Para justificar moralmente práticas sociais e instituições concretas, seria necessário recorrer a princípios morais autônomos que mantenham uma relação de precedência em relação às práticas sociais que visam justificar, os quais, por sua vez, existiriam independentemente de consensos sociais ou acordos entre indivíduos envolvidos. Proceder de forma contrária seria moralmente questionável, pois acordos voluntários sempre envolverão elementos contingentes e arbitrários do ponto de vista moral (por exemplo: o fato de uma das partes ser intelectualmente superior à outra). Seria ainda epistemologicamente duvidoso, pois não distinguiria o padrão de avaliação do objeto avaliado: a justificação de contratos individuais e específicos (objeto: um acordo) seria analisada a partir de um contrato coletivo geral dependente da convenção social vigente à época (padrão de avaliação: um acordo). Por essas razões, a posição original não pode ser compreendida como um contrato social do mundo real se quiser funcionar como um processo de justificação moral dos princípios de justiça rawlsiano, como Rawls mesmo reconhece, mas como uma forma de argumento contratual, que pressupõe a existência de um acordo hipotético entre partes hipotéticas (Sandel, 1998, pp. 109-113).

Devido à incapacidade de convenções sociais justificarem os princípios de justiça, algumas teorias ofereceram explicações alternativas. O exemplo clássico de tentativas nesse sentido é de Locke, para quem as leis de Deus e da Natureza oferecem o padrão último pelo qual pensar princípios de justiça anteriores às práticas sociais analisadas. Respostas como a de Locke, contudo, seriam incompatíveis com as aspirações do liberalismo deontológico, pois demandam que primeiro se pressuponha uma concepção de bem relacionada à ideia de leis divinas e naturais para então derivar os princípios de justiça (Sandel, 1998, pp. 116-119). De acordo com Sandel, essa incompatibilidade é enfatizada pelo fato de Rawls assumir que as partes na posição original são destituídos de laços morais prévios ou de qualquer forma de finalidade humana, sendo capazes de escolher seus próprios fins (Sandel, 1998, p. 117). Respostas como a de Locke contrariariam tanto a precedência da justiça sobre o bem, quanto a precedência do Eu sobre seus fins, razões pelas quais são insatisfatórias para o projeto político e filosófico do liberalismo deontológico.

Diante desse cenário, a posição original desempenha no pensamento rawlsiano a função de conferir bases mais sólidas para os princípios de justiça. No intuito de 
conferir às partes envolvidas no procedimento hipotético capacidades efetivamente humanas, Rawls concilia a posição original com princípios da rational choice. Segundo Sandel, além de oferecer o ponto de vista arquimediano pretendido por Rawls (procedimento hipotético, vision from far, mas com indivíduos dotados de uma racionalidade humana mínima, but not too far), o indivíduo racional pressuposto na posição original garantiria a precedência do procedimento justificatório sobre os princípios de justiça, ou seja, a precedência do padrão de avaliação sobre o objeto avaliado. Essa configuração certificaria que, por trás do véu de ignorância, as partes efetivamente escolham os princípios de justiça em um acordo consensual e deliberativo; ademais, por se tratar de um procedimento equitativo (fair), qualquer princípio de justiça derivado por esse meio seria moralmente justo e estaria, portanto, moralmente justificado (Sandel, 1998, pp. 125-126).

$\mathrm{Na}$ visão de Sandel, contudo, é questionável quão livres as partes estariam na deliberação sobre os princípios de justiça. Uma forma de interpretar a posição original seria considerá-la uma maneira de garantir que as partes envolvidas no acordo hipotético cheguem aos princípios corretos de justiça, e não a quaisquer princípios: "on this view, any agreements reached in the original position are fair, not because the procedure sanctifies just any outcome, but because the situation guarantees a particular outcome" (Sandel, 1998, p. 127). Nessa interpretação, os princípios de justiça elencados por Rawls representariam a única decisão coerente a que as partes poderiam chegar na posição original tal como desenhada. Consequentemente, todas as partes chegariam à mesma conclusão, dado que suas motivações foram homogeneizadas mediante o véu da ignorância. ${ }^{2}$

Como consequência imediata, essa interpretação transforma a forma como interpretamos a posição original. Menos do que uma escolha ou um acordo, a posição original implicaria uma descoberta dos princípios de justiça corretos (Sandel, 1998, pp. 128-129). Além disso, menos do que uma pluralidade de partes, a posição original suporia uma unidade avaliativa: um indivíduo intersubjetivo, representado pelo indivíduo racional por trás do véu da ignorância, reconheceria os princípios de justiça mais propícios à organização da estrutura básica da sociedade (Sandel, 1998, p. 131). Como consequência mais radical, essa interpretação colocaria a posição original em forte oposição aos pressupostos do liberalismo deontológico rawlsiano. Sai a pluralidade de indivíduos pressuposta por Rawls, bem mesmo a noção voluntarista de indivíduo, e entra a unidade do Eu junto com uma noção cognitiva do indivíduo baseada no autoconhecimento e na autodescoberta de seus valores; em suma: "what goes on in the original position is not a contract after all, but the coming to selfawareness of an intersubjective being" (Sandel, 1998, p. 132).

A coerência da teoria rawlsiana dependeria de uma ontologia social não oferecida por Rawls. ${ }^{3}$ Sandel exemplifica esse ponto ao contrastar três conceitos de comunidade (Sandel, 1998, pp. 147-154). Concepção instrumental: a comunidade adquire meros contornos instrumentais, pois os indivíduos cooperam social somente como forma de garantirem seus interesses privados. Concepção sentimental: a comunidade deriva do senso de benevolência e cooperação dos indivíduos, que não necessariamente possuem somente interesses privados e egoístas, mas podem 
possuir sentimentos legítimos em relação ao bem-estar dos demais indivíduos. Essa é a concepção de comunidade do próprio Rawls. Para Sandel, ambas concepções de comunidade são individualistas e, portanto, insuficientes para oferecer respostas aos problemas encontrados. A primeira é individualista na medida em que em que identifica interesses egoístas como razão para a cooperação social de indivíduos; a segunda, pois assume a individuação anterior dos sujeitos, excluindo a possibilidade de um sujeito intersubjetivo - o sujeito é único, seus desejos e interesses é que são comunitários.

Há ainda uma terceira concepção de comunidade: a concepção constitutiva. Para essa visão, a comunidade não é instrumental nem se limita aos desejos e interesses de sujeitos previamente individuados. Antes, a comunidade penetra a própria identidade dos sujeitos envolvidos; ela não representa aquilo que o sujeito possui ou escolhe, mas sim o que ele é. Para essa visão: (a) as fronteiras do Eu são abertas, e não estabelecidas previamente; (b) o Eu não escolhe seus fins por meio da autonomia, mas antes chega a eles por meio da reflexão sobre sua identidade num processo de descoberta, e não de escolha; (c) a pergunta correta, portanto, não é o que eu quero, mas quem eu sou (Sandel, 1998, p. 150). Embora essa concepção de comunidade não esteja presente no liberalismo deontológico, somente ela seria capaz de fundamentar a unidade do Eu e, consequentemente, a existência de sujeitos intersubjetivos. Somente ela, portanto, seria capaz de explicar por que na posição original um sujeito intersubjetivo descobre princípios de justiça, ao invés da imagem tradicional de partes que deliberam e escolhem consensualmente quais princípios deverão organizar a estrutura básica da sociedade.

Sandel havia dito que algumas ideias sobre o tipo de indivíduo que somos deveriam ser verdades para que a justiça possa ser considerada a primeira virtude social. A partir disso, ele buscou demonstrar os limites do projeto rawlsiano a esse respeito e, portanto, os limites da própria noção de primazia da justiça. Quando prestamos mais atenção àquilo que nos uni, aos nossos elementos comuns, a justiça não só perde sua precedência em relação às demais virtudes, como também pode se transformar num vício. Imagine, diz Sandel, uma família organizada com base na benevolência (Sandel, 1998, pp. 31-35). Tentar regular as relações humanas existentes na instituição familiar com base em noções de justiça é dissolver os sentimentos de benevolência existentes entre os indivíduos e separá-los ao invés de uni-los. Uma vez percebido os limites da justiça, a busca liberal pela neutralidade se ameniza, sendo possível e necessário introduzir concepções de bem da comunidade no debate político. Da política dos direitos liberal, passa-se à política do bem comum comunitária.

Diante das críticas colocadas por Sandel ao projeto de Rawls, cabe perguntar quais, se existentes, os limites do seu comunitarismo.

\section{O fim do liberalismo rawlsiano?}

Diante das críticas ao projeto da Rawls desenvolvidas por Sandel, essa 
seção analisa duas possíveis críticas ao projeto comunitarista do próprio Sandel. A primeira questionará sua noção de comunidade. A segunda foca na sua noção de agência humana. Se procedentes, ambas as críticas demonstrariam os limites de seu comunitarismo, bem como manteriam vivo o projeto rawlsiano.

\section{Que comunidade?}

Tanto a crítica de Sandel ao projeto rawlsiano, quanto sua proposta de uma política do bem comum pressupõem a noção de comunidade, que exerceria o papel de ente social intersubjetivo cujos valores compartilhados constituiriam a identidade dos indivíduos pertencentes a uma determinada prática e a um determinado contexto social. Porém, resta a dúvida: a qual comunidade Sandel tanto se refere? Responder a essa pergunta é fundamental para avaliar o sucesso das críticas comunitárias de Sandel ao projeto liberal, pois aborda o núcleo de toda sua ontologia social.

Podemos encontrar uma crítica à noção de comunidade presente em Sandel em Kymlicka. Para o autor, Sandel e outros autores comunitários frequentemente se referem a valores comunitários compartilhados, mas raramente oferecem exemplos de quais seriam esses valores (Kymlicka, 2002, p. 259). Uma das possíveis razões seria a inexistência desse senso de comunidade nos Estados-nação contemporâneos. Seria sintomático, portanto, o fato de esses autores fazerem referência a sociedades antigas ao tentarem oferecer exemplos concretos de comunidades. O principal problema com essa estratégica encontra-se no fato de que tais sociedades eram notadamente exclusivas, marginalizando diversos grupos sociais relevantes no atual cenário político e social. Mas se esses são os exemplos a serem oferecidos pelos autores comunitarista, como é possível falar em comunidade quando os valores compartilhados na verdade representam a forma de vida de uma parcela reduzida da população (geralmente branca, masculina e rica) impostos à parcela restante da população?

A solução desses autores, inclusive de Sandel, seria incluir na noção de comunidade aquela parcela da população historicamente marginalizada (Kymlicka, 2002). Haveria, assim, a necessidade de renovação ou atualização do conceito de comunidade, para a qual os exemplos históricos serviriam de inspiração. É questionável, porém, se qualquer tentativa de atualização do conceito de comunidade não acabaria na verdade por acentuar a inadequação do projeto comunitarista de uma política do bem comum.

Para demonstrar esse ponto, Kymlicka utiliza um dos poucos exemplos concretos oferecido por Sandel sobre a política do bem comum: a regulação da 
pornografia. Sandel é favorável a políticas de proibição da pornografia para certas comunidades se o conteúdo pornográfico representar uma ofensa à forma de vida compartilhada prevalecente naquele grupo social. Cabe questionar, porém, e esse ponto Sandel não esclarece, a qual forma de vida compartilhada ele se refere, bem como quem seriam os indivíduos ofendidos pela prática da pornografia. Para Kymlicka, o argumento de Sandel contrário à pornografia com base numa política do bem comum demonstra quão exclusivo a posição comunitarista pode ser (Kymlicka, 2002, pp. 259-260). Por exemplo, parcela do movimento feminista defenderá a proibição da pornografia por razões completamente distintas: a pornografia deve ser proibida não porque ofende a forma de vida da comunidade, mas exatamente porque conforma e reforça certas práticas comunitárias moralmente repreensíveis, como violência contra a mulher; subordinação feminina; estereótipos de gênero; entre outras (Kymlicka, 2002, pp. 259-260).

Se procedente ou não, a crítica feminista da pornografia revela quão complexo pode se tornar a tarefa de definir os valores compartilhados de uma comunidade, sobretudo nas sociedades contemporâneas. A inclusão na análise de grupos historicamente marginalizados corrói a unidade do sujeito intersubjetivo, cujos fins supostamente constituiriam nossas identidades como indivíduos. Com isso, a política do bem comum precisaria superar sérias objeções práticas para se mostrar uma alternativa concreta e viável ao projeto liberal rawlsiano. Como a crítica de Kymlicka demonstra, ainda não está claro como a unidade prevalece sobre a pluralidade do Eu, nem mesmo, portanto, como políticas do bem comum são capazes de suplantar a primazia da justiça nos Estados-nação contemporâneos. Eis o primeiro limite ao comunitarismo de Sandel.

\section{Que agência?}

Como visto, Sandel considera falsa a noção liberal de agência humana. Não escolhemos nossos fins, mas os descobrimos sem qualquer possibilidade de escolha. Consequentemente, o Eu não precede seus fins, mas é constituído por eles, de forma que não podemos distinguir as pessoas que somos dos fins que possuímos. Mais do que isso, nossos fins são determinados pelas práticas sociais das quais fazemos parte, pelos papéis sociais que ocupamos. Por sermos indivíduos situados socialmente, com valores comunitários constitutivos de nossa personalidade, nossas vidas serão melhores na medida em que possuímos as condições necessárias para tomada de consciência de nossos fins constitutivos, de quem realmente somos. É necessária, portanto, uma política do bem comum, e não dos direitos; uma política que nos permita 
encontrar a concepção de bem comum que não conseguiríamos encontrar sozinhos, e não uma política que nos permita questionar e revisar a todo momento quem somos (Kymlicka, 2002, p. 224).

A questão a ser respondida a esse respeito é: a nova interpretação de agência humana proposta por Sandel é realmente capaz de justificar políticas perfeccionistas de promoção de certas concepções de vida boa pelo Estado, em detrimento da neutralidade liberal? Determinar o alcance da agência humana é fundamental para determinar o alcance do argumento comunitário de Sandel contra o projeto liberal de Rawls. Se valores comunitários determinam tão fortemente quem somos, parece razoável a defesa de uma política do bem comum. Porém, se os indivíduos preservam a capacidade de escolha e de autodeterminação de sua concepção de vida boa, a despeito das críticas de Sandel, não parece haver boas razões para se descartar a neutralidade liberal em prol do projeto comunitarista.

$\mathrm{Na}$ visão de Kymlicka, o contraste entre as visões liberal e comunitarista de agência humana na verdade oculta semelhanças mais fundamentais. Embora não compreendamos nossa agência em termos puramente voluntários, admitindo a importância de valores comunitários e de processos de autoconhecimento, não achamos que esses elementos substituam ou impeçam julgamentos sobre quais vida acreditamos valer a pena ser vivida (Kymlicka, 2002, p. 226). Seria equivocado supor que a visão cognitiva de agência proposta por Sandel nos torne incapaz de avaliar e, eventualmente, de nos distanciarmos dos valores sociais herdados nos quais nos encontramos. Por isso às vezes, apesar de compartilharmos valores e possuirmos papéis sociais que conferem sentido às nossas vidas, muitas vezes passamos a descordar daquilo que descobrimos: "no matter how deeply implicated we find ourselves in a social practice, we feel capable of questioning whether the practice is a valuable one - a questioning that is not meaningful on Sandel's account" (Kymlicka, 2002, p. 226).

Kymlicka argumenta que o próprio Sandel acaba por admitir essa possibilidade. Ao final, embora difícil, o processo de autodescoberta habilita o sujeito a se distanciar dos seus fins constitutivos, a escolher, dentre todos propósitos e valores conflitantes, aqueles que constituirão sua identidade (Kymlicka, 2002, p. 226). Ao admitir essa possibilidade, prossegue Kymlicka, não fica claro como a concepção de Sandel se diferencia da visão liberal de agência. Embora a ênfase de Rawls seja na escolha, enquanto a de Sandel seja na descoberta, ambos concordam que o indivíduo é capaz de revisar seus valores e julgar suas práticas, não importa quão constitutivos de sua identidade eles venham a ser e quão demandante venha a ser o processo. Para ambos, então, a pessoa precede seus fins, não importa onde deva ser traçada a fronteira do $\mathrm{Eu}$ - questão que passa a ser afeta à filosofia da mente ou à 
psicologia, não mais ao campo da filosofia política (Kymlicka, 2002, p. 227).

Em suma, ao admitir a possibilidade de revisarmos nossos fins constitutivos, a posição comunitarista falharia em oferecer um contraponto, ao menos do ponto de vista prático, ao liberalismo rawlsiano. Eis o segundo limite à teoria de Sandel:

\begin{abstract}
Perhaps their [communitarians'] idea of our embeddedness is not incompatible with out rejecting the attachments we find ourselves in. But then the advertised contrast with the liberal view is a deception, for the sense in which communitarians view us as independent of them, and the sense in which communitarians view practical reasoning as a process of 'self-discovery' incorporates the sense in which liberals view it as a process of judgement and choice. The differences would be merely semantic. And once we agree that individuals are capable of questioning and rejecting the value of the community's way of life, then the attempt to discourage such questioning through a 'politics of the common good' seems an unjustified restriction on people's self-determination (Kymlicka, 2002, pp. 227-228).
\end{abstract}

\title{
Reinterpretando a primazia da justiça
}

Além dos dois limites ao comunitarismo de Sandel considerados acima, centrados nas noções de comunidade e de agência, parece plausível questionar se sua crítica ao projeto rawlsiano considera corretamente o papel desempenhado pela ideia de primazia da justiça. Estaria Rawls sustentando a primazia da justiça em todas as condições e circunstâncias sociais? Uma leitura rigorosa de seu pensamento, sobretudo da sua obra Justice as Fairness, identificará ressalvas feitas pelo próprio Rawls sobre os limites de sua teoria. Embora essas ressalvas enfraqueçam o alcance de suas afirmações, elas as tornam mais consistentes e, portanto, difíceis de serem afastadas dentro dos seus limites de aplicação. Assim, como argumento filosófico, a crítica de Sandel parece insuficiente para afastar a alegação de primazia da justiça sobre as demais virtudes sociais como concebida por Rawls; como argumento político, é incapaz de justificar o abandono do discurso liberal em prol do discurso do bem comum.

Ao resumir as ideias fundamentais de sua teoria da justiça em Justice as Fairness, Rawls dedica boa parte das primeiras cinco seções do primeiro capítulo para identificar e esclarecer as condições de aplicação de sua teoria. Esse detalhe topológico é sintomático. Antes de apresentar os principais elementos de sua teoria da justiça, Rawls estabelece as condições nas quais os princípios de justiça serão derivados e, posteriormente, aplicados. Determinar a aplicabilidade de sua teoria da justiça a certas comunidades e estruturas sociais, assim, exige compreensão quanto aos critérios 
estabelecidos de antemão pelo próprio Rawls.

A esse respeito, Rawls reitera em diversas passagens que o objetivo de sua teoria é identificar princípios de justiça capazes de ordenar a estrutura básica de sociedades democráticas bem organizadas e marcadas pelo fato do pluralismo. Ou seja, sua teoria toma como parâmetro: (a) a estrutura básica da sociedade; (b) sociedade democráticas; (c) sociedades bem ordenadas; (d) e sociedades marcadas pelo fato do pluralismo. São sob essas condições que a justiça deve ser interpretada como a primeira virtude social:

\begin{abstract}
We view political philosophy as realistically utopian: that is, as probing the limits of practicable political possibility. Our hope for the future of our society rests on the belief that the social world allows at least a decent political order, so that a reasonably just, though not perfect, democratic regime is possible. So we ask: What would a just society be like under reasonably favorable but still possible historical conditions, conditions allowed by the laws and tendencies of the social world? What ideals and principles would such a society try to realize given the circumstances of justice in a democratic culture as we know them? These circumstances include the fact of reasonable pluralism. This condition is permanent as it persists indefinitely under free democratic institutions (...) The principles of justice provide a response to the fundamental question of political philosophy for a constitutional democratic regime (Rawls, 2001, p. 4 e 7).
\end{abstract}

Essas delimitações delineiam sérias ressalvas à crítica de Sandel, sobretudo porque normalmente vem respaldada por exemplos, de comunidades para as quais a justiça supostamente não representaria a primeira virtude social, que extrapolam as condições estabelecidas por Rawls. Como visto acima, Sandel fundamenta sua crítica com recurso a instituições como a família ou comunidades antigas, nas quais predominariam a benevolência e a solidariedade, e não o senso de justiça, como a virtude das virtudes. Essa estratégia argumentativa, contudo, está sujeita a uma série de ressalvas e se mostra, no fundo, inadequada. Rawls deixa claro que sua teoria da justiça apenas pretende regular a estrutura básica de uma sociedade, e não das demais instituições internas a essa sociedade, que colocariam problemas específicos de justiça local (Rawls, 2001, p. 10).

Mais especificamente, o objetivo de Ralws é pensar princípios que regulem sociedades bem ordenadas marcadas pelo fato do pluralismo. Atacar a primazia da justiça com base no exemplo de famílias ou de sociedades antigas no qual prevaleceriam sentimentos de benevolência e de fins compartilhados $^{4}$, assim, apenas realçaria o ponto de que a primazia alegada por Ralws não é universal e incondicional, com o qual ele mesmo parece estar de acordo: 
(...) the fact of political pluralism limits what is practicably possible under the conditions of our social world, as opposed to conditions in other historical ages when people are often said to have been united (though perhaps they have never been) in affirming one comprehensive conception (Rawls, 2001, p. 4).

Sendo assim, para realmente questionar o projeto rawlsiano, Sandel precisaria demonstrar como as sociedades democráticas contemporâneas não são marcadas pelo fato do pluralismo ou como esse pluralismo pode ser superado. Não foi essa, porém, a estratégia adotada e, ainda que fosse, fica difícil saber como ela poderia ser bem-sucedida diante dos argumentos analisados na seção anterior contra a noção de comunidade comunitarista.

\section{Considerações finais}

A despeito da contundência do argumentos de Sandel em busca de uma nova ontologia social, este artigo buscou demonstrar dois limites práticos da sua alternativa baseada numa política do bem comum. Com base nos argumentos de Kymlicka, demonstramos, por um lado, as limitações existentes na ideia de comunidade defendida por Sandel, incapaz de sustentar uma política coerente baseada no bem comum; de outro, os limites práticos de sua noção de agência humana, que, para os fins de uma filosofia política, guarda mais semelhanças do que diferenças em relação à noção liberal. Por fim, argumentamos que as objeções levantadas por Sandel são incapazes de afetar a estrutura básica do projeto rawlsiano. Dentro dos limites estabelecidos pelo próprio Rawls, continua procedente sua concepção de justiça como a primeira virtude social na organização da estrutura básica da sociedade, embora isso não impossibilite a coexistência da justiça com demais valores comunitários.

\section{Referências:}

DWORKIN, Ronald. A Matter of Principle. Cambridge, USA: Harvard University Press, 1985.

FORST, Rainer. Contexts of Justice: Political Philosophy beyond Liberalism and Communitarianism. Berkeley: University of California Press, 2002.

FREEMAN, Samuel. Original Position. The Stanford Encyclopedia of Philosophy. Winter 2016.2 Disponível em: <https://plato.stanford.edu/archives/win2016/entries/original-position/>. 
KYMLICKA, Will. Liberal Individualism and Liberal Neutrality. Ethics, v. 99, n. 4, p. 883-905, 1989.

. Contemporary Political Philosophy. Oxford: Oxford University Press, 2002.

RAWLS, John. A Theory of Justice. Massachusetts: Belknap, 1999. . Justice as Fairness: A restatement. Massachusetts: Belknap, 2001.

SANDEL, Michael J. The Procedural Republic and the Unencumbered Self. Political Theory, v. 12, n. 1, p. 81-96, 1984.

Press, 1998.

. Liberalism and the Limits of Justice. Cambridge: Cambridge University

TAYLOR, Charles. Philosophical Arguments. Cambridge, USA: Harvard University Press, 1997.

WALZER, Michael. The Communitarian Critique of Liberalism. Political Theory, v. 18, n. 1, p. 6-23, 1990.

\footnotetext{
${ }^{1}$ Importante ressaltar, na linha de Charles Taylor, que as divergências políticas e filosóficas são de ordens distintas. É possível haver divergências filosóficas profundas entre liberais e comunitários e ao mesmo tempo convergência a respeito da melhor solução política para um problema. Também é verdade, contudo, como o próprio Taylor reconhece, que essas duas dimensões estão conectadas, de forma que suas concepções filosóficas o conduzirão, em alguns casos, a certos posicionamentos políticos em detrimentos de outras alternativas existentes. Ao contrapor a política dos direitos e da justiça à política do bem comum, tentei ressaltar as conexões existentes entre ambas as dimensões. Isso não diz nada, porém, a respeito da agenda política específica de cada autor, quando entram em jogo soluções concretas para problemas determinados. Cf. (Taylor, 1997).

2 Segundo Sandel, o próprio Rawls confirmaria essa interpretação da posição original, a despeito da linguagem utilizada por ele, que sugeriria escolha, debate, deliberação (Sandel, 1998, p. 127).

${ }^{3}$ Charles Taylor compartilha dessa leitura da obra de Sandel. No fundo, ela diria respeito à necessidade de repensarmos nossa concepção de ontologia social. Cf. (Taylor, 1997, pp. 181-203).

${ }^{4}$ Assumimos, para fins deste argumento, a homogeneidade alegada pelos comunistaristas neste último caso, embora ela já tenha sido colocada em xeque na seção anterior.
} 